\title{
O PRINCÍPIO EDUCATIVO DA PRODUÇÃO ASSOCIADA: UM OLHAR A PARTIR DA ORGANIZAÇÃO COLETIVA DOS TRABALHADORES E DA GESTÃO DEMOCRÁTICA DO PROCESSO DE TRABALHO1
}

\author{
Anderson Roik ${ }^{2}$ \\ Danuta Estrufika Cantóia Luiz ${ }^{3}$ \\ José Henrique de Faria ${ }^{4}$
}

\begin{abstract}
Resumo
Trata-se de revisão teórica que objetiva sistematizar a categoria princípio educativo da produção associada, pautando-se nos conceitos pedagogia da produção associada e cultura do trabalho elaborados por Tiriba e, nos estudos sobre as condições para uma gestão democrática do processo de trabalho e o conceito de organização coletivista de produção associada desenvolvidos por Faria. 0 princípio educativo que se realiza nas organizações coletivistas de produção associada sob uma gestão democrática do processo de trabalho possibilita, a partir da aprendizagem coletiva na e pela práxis, forjar uma nova cultura do trabalho e estabelecer novas concepções de trabalho, de vida e de mundo.
\end{abstract}

Palavras-chave: princípio educativo do trabalho, gestão democrática, organização coletiva.

THE EDUCATIVE PRINCIPLE OF COLLABORATIVE PRODUCTION: A LOOK FROM THE COLLECTIVE ORGANIZATION OF LABOURERS AND THE DEMOCRATIC MANAGEMENT OF WORK PROCESS

\begin{abstract}
This article is a theoretical review and aims to systematize the principle education of collaborative production, guided on concepts pedagogy of collaborative production and work culture designed by Tiriba and on studies about the conditions for a democratic management of work process developed by Faria. The educative principle that take place on the collectivist organizations of collaborative production under a democratic management of work process enable from the collective learning and for praxis, forge a new work culture and stabilish new conceptions of work, of life and of world.
\end{abstract}

Key-words: educative principle of work, democratic management, collective organization.

1DOI: https://doi.org/10.22409/tn.16i31.p27384

${ }^{2}$ Mestrado em Engenharia de Produção pela Universidade Tecnológica Federal do Paraná, UTFPR e Doutorando pelo Programa de Pós-Graduação em Ciências Sociais Aplicadas da Universidade Estadual de Ponta Grossa, UEPG. Servidor da Universidade Estadual do Centro-Oeste, UNICENTRO. E-mail: andersonroik@hotmail.com

${ }^{3}$ Doutorado em Serviço Social pela Pontifícia Universidade Católica de São Paulo, PUCSP. Professora Associada da Universidade Estadual de Ponta Grossa, UEPG, atuando no Curso de Serviço Social e no Programa de Pós-graduação em Ciências Sociais Aplicadas. E-mail: danutaluiz88@gmail.com ${ }^{4}$ Doutorado em Administração pela Universidade de São Paulo, USP e Pós-Doutorado em Labor Relations pelo Institute of Labor and Industrial Relations, ILIR, University of Michigan. Professor Titular Sênior da Universidade Federal do Paraná, UFPR, atuando no Programa de Pós-Graduação em Administração; e Coordenador do Programa de Mestrado em Governança e Sustentabilidade do Instituto de Administração e Economia do Mercosul, ISAE-PR. E-mail: jhfaria@gmail.com 


\section{Introdução}

No processo de fundamentar teoricamente o princípio educativo do trabalho 4 no contexto da produção associada, algumas lacunas e equívocos conceituais foram identificados, exigindo a proposição de uma nova categoria a fim de solucionar essas questões e, também, enriquecer a discussão sobre o princípio educativo do trabalho. Esta categoria será aqui denominada princípio educativo da produção associada.

Por seu turno, a partir de uma abordagem teórica, este artigo tem por objetivo discutir o princípio educativo da produção associada, apoiando-se nos conceitos pedagogia da produção associada e cultura do trabalho elaborados por Tiriba e, nos estudos sobre as condições para uma gestão democrática do processo de trabalho e o conceito de organização coletivista de produção associada - OCPA desenvolvidos por Faria. Tal opção reside no fato de que ambas as abordagens dos pesquisadores se complementam e sua articulação pode fornecer importantes contribuições para a temática em estudo, bem como possibilitar uma leitura correta do concreto e, assim, permitir uma correta intervenção a fim de transformá-lo.

Tiriba $(1999,2001,2006,2007,2010)$ se dedica aos processos de formação humana - educativos e culturais - das experiências de produção associada das classes populares em seus movimentos e em suas práticas de produção das condições de sua existência. Daí o conceito de pedagogia da produção associada e cultura do trabalho.

Faria (2009, 2011, 2017a, 2017b), por sua vez, a partir de seus estudos sobre a gestão das organizações - relações de poder, processo de trabalho e controle na gestão do processo de trabalho - propõe uma reflexão crítica sobre os critérios para uma gestão democrática. Além disso, desenvolve uma crítica aos equívocos conceituais relacionados às experiências autogestionárias e, estabelece a necessária distinção conceitual entre os empreendimentos que se autodenominam autogestionários e a autogestão social, dando origem ao conceito de OCPA.

\footnotetext{
4 Titton (2008) apresenta a distinção entre princípio educativo do trabalho e o trabalho como princípio educativo. Segundo Titton (2008, p. 4), Pistrak - no livro Fundamentos da Escola do Trabalho - explica essa diferença: princípio educativo do trabalho corresponde ao processo mais amplo de educação que se realiza "[...] por meio do trabalho na forma social em que assume num modo determinado de produção da vida"; e, trabalho como princípio educativo consiste na "[...] utilização do trabalho material socialmente útil como base para a organização de um sistema de ensino". Neste artigo, ambos os termos serão entendidos como o processo mais amplo de educação.
} 
Neste artigo, inicialmente, é colocado o tema da autogestão social relacionando a produção associada e o princípio educativo do trabalho. Num segundo momento, é abordada a pedagogia da produção associada discutindo-se o processo educativo que nela se desenrola e, também, as perspectivas de se forjar uma nova cultura do trabalho. No terceiro momento, são apresentadas as OCPA conceituando e delimitando as unidades básicas para uma possível autogestão social, bem como as condições para que a gestão do processo de trabalho seja efetivamente democrática. Por último, são feitas as considerações finais.

Abordar o tema do princípio educativo do trabalho e, mais especificamente, o princípio educativo da produção associada, além de ser um desafio, torna-se, no plano da práxis ${ }^{5}$, uma arma valiosa para a superação das relações sociais capitalistas afastando o imobilismo que parece preponderar.

\section{A produção associada e o princípio educativo do trabalho: caminhos para a autogestão social}

A autogestão social, segundo Faria (2009, p. 338), propõe "[...] uma noção de economia a partir do que é necessário produzir e uma noção de política enquanto realização em todos os níveis - e sem intermediários - de todos os interesses por todos os sujeitos coletivos". Assim, para o autor, a economia deixa de estar orientada a questão da lucratividade, sendo a exploração dos trabalhadores e a sua dominação pelo capital destruídos.

A autogestão social consiste em uma prática com um projeto político oposto a heterogestão e ao sistema de capital, uma transformação radical da sociedade nos planos econômico, político e social. Não se trata da democratização da economia capitalista, mas da alteração de seus fundamentos (FARIA, 2009).

\footnotetext{
5 "A praxis na sua essência e universalidade é a revelação do segredo do homem como ser ontocriativo, como ser que cria a realidade (humano-social) e que, portanto, compreende a realidade (humana e não-humana, a realidade na sua totalidade). A praxis não é atividade prática contraposta à teoria; é determinação da existência humana como elaboração da realidade" (KOSIK, 2002, p. 222). Para (VÁZQUEZ, 2011), "em suma, a práxis se apresenta como uma atividade material, transformadora e adequada a fins. Fora dela, fica a atividade teórica que não se materializa, na medida em que é atividade espiritual pura. Mas, entretanto, não há práxis como atividade puramente material, isto é, sem a produção de fins e conhecimentos que caracteriza a atividade teórica". ( p. 239).
} 
A autogestão se inscreve no movimento de ampliação da democracia, por isso não basta que sua existência se limite às unidades produtivas, pois seu alcance é social. A autogestão social não é nem uma mera extensão da democracia representativa formal a todas as esferas da sociedade, nem uma democracia ou gestão participativa e nem uma correção dos princípios centralizadores da democracia popular (FARIA, 2009, p. 352).

Na perspectiva de Faria (2009), a autogestão tem por objetivo eliminar as estruturas autoritárias da sociedade e das suas organizações. Vai além de mera proposta democratizante no âmbito da gestão participativa que apenas cria grupos de trabalho autônomos ou acaba com determinados graus de autoridade nas organizações. Não se trata, pois, da panaceia participativa conciliadora que pressupõe o fim do conflito entre capital e trabalho e, além disso, o que a autogestão for não está pré-determinado por ninguém.

A autogestão social é uma mudança radical e revolucionária que altera qualitativamente o sistema de capital. Trata-se da criação de outro e superior modo de produção e de gestão social (FARIA, 2009).

A produção associada e a autogestão, segundo Tiriba e Fischer (2012, p. 619) "[...] situam-se no contexto de afirmação e de formação de trabalhadores e trabalhadoras para a construção de uma 'sociedade dos produtores livremente associados'”. E, no horizonte da emancipação humana, as categorias históricas produção associada e autogestão se relacionam e se articulam e, no interior do modo de produção capitalista, são possibilidades concretas de experimentação.

Para Tiriba (2001, p. 182), a autogestão:

[...] consiste em que cada um possa constituir-se em senhor de si mesmo, de seu trabalho, como sujeito criador da história e construtor de uma nova ordem social, o que pressupõe uma relação estreita entre teoria e prática, entre o que fazer no chão-da-produção e os fundamentos filosóficos e científicos-tecnológicos relativos ao mundo do trabalho.

De acordo com Brito (2010, p. 115), a autogestão deve ser compreendida como "[...] um aprendizado cotidiano em torno de um saber historicamente acumulado, que diz respeito aos fundamentos da gestão num regime de propriedade coletiva".

As relações econômico-sociais e culturais em que os trabalhadores têm a propriedade e/ou posse coletiva dos meios de produção estão relacionadas ao termo produção associada e autogestão (TIRIBA; FISCHER, 2012). Diferem da 
heterogestão, pois são seus integrantes que criam e recriam os princípios, as regras e as normas de convivência que vão reger o trabalho associado e autogestionário. Para as autoras, a "[...] organização do trabalho (material e simbólico) é mediada e regulada por práticas que conferem aos sujeitos coletivos o poder de decisão sobre o processo de produzir a vida social” (TIRIBA; FISCHER, 2012, p. 614).

A participação direta de todos os produtores - e não apenas representativa na tomada de decisões básicas seja em relação às organizações econômicas como à vida em sociedade, consiste no atual desafio das relações sociais (TIRIBA, 2001). É importante, nesse contexto, investigar e compreender as motivações que fazem com que os trabalhadores permaneçam mobilizados em torno do empreendimento cooperativo, considerando as condições de dificuldade em que essa luta se desenvolve.

Assim como ensinou Gramsci, é necessário olhar para as iniciativas que levem ao aprendizado e ao desenvolvimento das classes subalternas. "Estas, mais do que preocupar-se em resistir à opressão, são chamadas a buscar formas para sair da submissão e inventar os termos de uma nova sociedade" (SEMERARO, 1999, p. 71).

Neste sentido, segundo Luiz (2013, p. 98),

Permanece também a importância do fomento às práticas sociais pedagógicas e democráticas que socializem e universalizem 0 conhecimento e consequentemente a criação de uma cultura política madura nas classes / grupos sociais, como enfrentamento aos mecanismos de poder e de dominação hegemônicos, como rupturas moleculares frente ao instituído.

Para Luiz (2013), numa perspectiva gramsciana, a via cultural e ético-política são possibilidades de enfrentamento das contradições da sociedade capitalista. Tal enfrentamento é possível "[...] mediante o fomento da potencialidade das massas, de seu protagonismo consciente, ativo e organizado - desencadeado por um processo de rupturas que levará a edificação da emancipação social como um caminho contrahegemônico" (LUIZ, 2013, p. 20).

Para Semeraro (1999, p. 73) "[...] o ponto central das reflexões de Gramsci se prende à formação de novos sujeitos sociais que visam à construção de um projeto de sociedade aberto à participação de todos os trabalhadores". Para Gramsci, a vida em sociedade comporta "[...] uma práxis política consciente e coletiva que visa 
transformar a realidade, combate os privilégios e promove o protagonismo das massas espoliadas e excluídas" (SEMERARO, 1999, p. 79).

Diante da contraditoriedade da realidade decorrente do modo de produção capitalista, Tiriba e Picanço (2010), afirmam que passam a (re)surgir ou a se manifestar com maior intensidade formas de trabalho cujo sentido não se limita à reprodução do capital.

É certo que, se de um lado o sistema de capital leva às últimas consequências o processo de exploração da força de trabalho, inovando e precarizando - ainda mais - as formas de apropriação de sua energia física e psíquica, de outro, contraditoriamente, a produtividade demandada pelo capital, ao mesmo tempo em que obriga os trabalhadores a estabelecer determinadas formas de relação entre capital e trabalho, os impele a recriar antigas e novas relações econômico-sociais e, por consequência, repensar o sentido mesmo da práxis produtiva (TIRIBA; PICANÇO, 2010, p. 25).

Daí a origem das diversas formas de produção - economia solidária, economia cooperativa, incubadoras populares, economia popular da produção associada - que, diferentes do modelo hegemônico capitalista, abrem caminho para uma nova cultura do trabalho centrada na produção de bens e serviços para responder às necessidades humanas. Mesmo que inseridas no campo das contradições do sistema de capital e das próprias contradições e limites internos destas formas de produção, elas são o germe para novas relações e práticas educativas e novos vínculos entre economia, educação, produção e sociedade (FRIGOTTO, 2010).

É na apreensão dos saberes e fazeres, tecidos na cotidianidade desses homens e mulheres que buscam se apropriar do processo de produção em sua totalidade - seja na mais complexa ou formas ou modalidades mais simples -, que se encontram "[...] os elementos que favoreçam a formação integral e omnilateral de um novo homem" (TIRIBA; PICANÇO, 2010, p. 20). Afinal, no processo dialético de fazer, pensar, criar e recriar o mundo "[...] o trabalho é o princípio educativo e, ao mesmo tempo, uma das formas pelas quais, com a luta dos trabalhadores, é possível fazer germinar os embriões de uma nova cultura do trabalho" (TIRIBA; PICANÇO, 2010, p. 29).

Tiriba e Fischer (2012) ressaltam que, para Marx, a produção associada consiste na célula da sociedade dos produtores livres associados, ainda que limitada 
sob a égide capitalista. No entanto, é somente com o poder político nas mãos das classes trabalhadoras que será possível a derrota do capitalismo.

Enquanto potencialidades, a partir da produção associada, poderiam emergir processos educativos que "[...] desenvolvam a autonomia e elevem o senso comum a uma visão unitária e crítica da realidade, além da constituição de laços de solidariedade e igualdade para uma nova cultura do trabalho, centrada na perspectiva de novas relações sociais" (BARROS, 2010, p. 194). Quando se tem por objetivo uma economia de novo tipo, diferente do capitalismo e com vistas à emancipação humana, torna-se necessário fomentar e potencializar os elementos educativos para uma nova cultura do trabalho e novas relações sociais.

Tiriba (2001) defende que é pela práxis que o homem transforma a realidade. Isso também se aplica ao campo da produção associada "[...] tanto para aqueles que tiveram acesso a uma escolarização básica, que lhes permitiu apropriar-se dos fundamentos científico-tecnológicos do mundo do trabalho, como para aqueles que, em maior ou menor grau, não tiveram o mesmo privilégio [...]" (TIRIBA, 2001, p. 184).

Para os trabalhadores, é na produção associada que reside a "[...] possibilidade de contrariar o sentido de suas vidas e de seu trabalho de subverter a lógica que durante séculos o capital imprimiu às suas práticas trabalhistas". (TIRIBA, 2001, p. 195). Os trabalhadores na produção associada estão diante de um novo desafio, uma nova realidade que consiste em pensar e criar o processo produtivo. Para isso é necessário se apropriar dos segredos da ciência e da gestão, além da posse dos meios de produção.

$\mathrm{Na}$ perspectiva de Gramsci, a gestão da produção associada pressupunha a capacidade de cada trabalhador para administrar seu trabalho de acordo com os interesses coletivos. Participar do processo produtivo significaria ir mais além da participação por representação e também favorecer uma organização que permitiria a interferência coletiva e cotidiana no conteúdo e na forma de produção. Para o trabalhador associado, viver e administrar o processo de produção lhe permitiria a elaboração crítica da atividade intelectual existente em um determinado grau de desenvolvimento, em consonância com o trabalho manual; permitiria redimensionar sua práxis em função de uma nova concepção de mundo, fundamentada em um projeto de vida que busca a hegemonia do homem e de seu trabalho. Mas se, de um lado a transformação da realidade faz-se pela práxis, de outro, também é necessária a consciência desta mesma práxis e a superação do sentido comum de que o prático se reduz ao produtivo (TIRIBA, 2001, p. 195). 
A partir do pensamento de Frigotto (1999), Tiriba (2001, p. 210) afirma que, "[...] tendo ou não acesso à escola, os trabalhadores produzem e acumulam conhecimentos, em determinadas circunstâncias, em determinadas relações sociais".

O cotidiano do trabalho da produção associada se constitui como instância possível de mediação entre mundo da cultura e mundo da produção, especialmente para os trabalhadores expulsos do mercado formal de trabalho e expulsos dos bancos escolares. Os trabalhadores associados, no processo produtivo, "[...] podem descobrir que, sob os limites impostos pela sociedade de mercado, é possível - desde o 'pé-de-

obra', desde a práxis - inventar relações sociais e econômicas que, de alguma maneira contrariem a lógica capitalista" (TIRIBA, 1999, p. 5).

Na produção associada se promove a articulação dos diversos saberes dos trabalhadores, diferentemente da lógica capitalista do controle e da dificuldade de acesso ao segredo do processo produtivo. Trata-se de um espaço singular de produção de conhecimentos (TIRIBA, 2001).

A apreensão e problematização das categorias produção associada e autogestão são possíveis "[...] se consideradas as condições objetivas/subjetivas em que, nos diversos espaços/tempos históricos, as classes trabalhadoras tomam para si os meios de produção" (TIRIBA; FISCHER, 2012, p. 617).

Com esta perspectiva, será discutido o conceito pedagogia da produção associada, abordando o processo educativo que se desenrola quando os trabalhadores se organizam para produzir suas condições de vida associadamente e, também, as possibilidades que se abrem para consolidação de uma nova cultura do trabalho.

\section{Pedagogia da produção associada: processo educativo e cultura do trabalho}

Kuenzer (1986) desenvolveu o conceito pedagogia da fábrica buscando compreender como se processam as relações trabalho/educação no âmbito da própria fábrica capitalista e, também, elucidar os modos como a empresa capitalista educa o trabalhador. Como analogia e ao mesmo tempo crítica, Tiriba (2001), utiliza o conceito pedagogia(s) da produção associada para poder compreender os processos educativos que se realizam nos espaços coletivos de produção da vida tão característicos no contexto da crise do emprego. Espaços estes em que, sob certos 
limites e dentro de suas possibilidades, os trabalhadores (em tese livremente associados) se contrapõem a lógica perversa do capital reinventando o cotidiano do trabalho.

Conforme apresenta Frigotto (2010) no prefácio do livro O trabalho como princípio educativo no processo de produção de uma "outra economia", contrapondo e refutando a pedagogia do capital ou pedagogia da fábrica capitalista, encontra-se a pedagogia da produção associada. Entende-se, assim, que é no espaço contraditório das relações sociais de produção capitalistas que a pedagogia da produção associada vai forjando (ou pode vir a forjar) uma nova cultura do trabalho.

A partir do estudo de Kuenzer ${ }^{6}$ (1986) sobre as relações pedagógicas no interior da fábrica, Tiriba (2001, p. 198) destaca que, "[...] é a partir das relações concretas de produção que o trabalhador, além de aprender os conhecimentos técnicos, aprende os valores e comportamentos necessários para tornar-se um 'bom trabalhador'". Isso porque, os homens produzem - sob determinadas relações sociais - o saber sobre o trabalho na prática concreta dos processos produtivos.

Partindo das contribuições de Gramsci, Tiriba (2001, p. 29) infere que: "[...] a experiência viva e histórica dos processos produtivos geridos pelos próprios trabalhadores tem representado para seus atores 'uma magnífica escola de experiência política e administrativa'”.

Os processos produtivos são entendidos "[...] como processos pedagógicos que medeiam as condições objetivas e subjetivas da cultura do trabalho" (TIRIBA, 2001, p. 32). Por isso, a autora chama a atenção para o caráter educativo das novas formas de trabalho - a produção associada - que são empreendidas pelos próprios trabalhadores no quadro da crise do emprego. Ela traz para discussão a pedagogia da produção associada, revelada a partir das motivações e práticas dos trabalhadores associados. Sua análise contempla a organização e gestão dos empreendimentos, as relações de mercado, as instâncias de produção e socialização do saber e os vínculos que se estabelecem com o governo, os empresários, as instituições de apoio e outras redes de ação coletiva (TIRIBA, 2001).

\footnotetext{
${ }^{6} \mathrm{~A}$ própria autora adverte que se, de um lado, o homem produz conhecimento à medida que produz as condições de sua existência, de outro, o conhecimento produzido pelos trabalhadores não é equivalente ao saber historicamente produzido pela burguesia ao longo do capitalismo, dado que os primeiros não desfrutam do acesso aos instrumentos teórico-metodológicos que nos permita sistematizar seu saber (TIRIBA, 2001, p. 198).
} 
A abordagem da pedagogia da produção associada requer atenção sobre o fazer e o saber dos setores populares. Para Tiriba (2010, p. 97), "[...] ela requer o ir e vir na teoria e na prática, na vida real dos trabalhadores, resignificando os sentidos ético-políticos de suas estratégias de trabalho e de sobrevivência".

O trabalho fabril, na perspectiva gramsciana, seria o lugar de uma pedagogia ativa, sendo a práxis o eixo da construção da realidade social. A fábrica então "[...] seria o locus da produção de intelectuais orgânicos do proletariado que, ao invés de executar um programa pré-estabelecido pelos capitalistas, se tornariam sujeitos capazes de gestionar técnica e economicamente o processo produtivo" (TIRIBA, 1999, p. 5). Vale destacar que, para o sucesso de um projeto de transformação social é necessária a incorporação de outros setores sociais.

A pedagogia da produção associada, ao se colocar na perspectiva de emancipação das classes trabalhadoras e ter por horizonte a subversão do capitalismo, busca contribuir a criação e recriação de uma cultura do trabalho de novo tipo. Uma cultura do trabalho "[...] que possa materializar um outro sentido para o próprio trabalho, para economia e para as relações de convivência, não apenas no interior da unidade produtiva, mas também na comunidade local e no território mais amplo das relações sociais" (TIRIBA, 2006, p. 121-122).

Resgatando o pensamento de Gramsci, Semeraro (2010), afirma que, em suas organizações e com o desenvolvimento de suas subjetividades, os trabalhadores "[...] podem criar uma outra cultura e experimentar novas formas de produção socializada, pondo-se como alternativa ao projeto mecânico e destrutivo determinado pelo capital".

A instauração de uma nova cultura do trabalho exige processos educativos com ênfase nos aspectos filosóficos e políticos das formas de convivência humana. Afinal, para que se possa dar um novo sentido às relações sociais e econômicas é necessária a construção de novos conhecimentos e valores (TIRIBA, 2001).

A cultura do trabalho é definida conceitualmente como:

Conjunto de conhecimentos teórico-práticos, comportamentos, percepções, atitudes e valores que os indivíduos adquirem e constroem a partir de sua inserção nos processos de trabalho e/ou da interiorização da ideologia sobre trabalho, todo o qual modula sua interação social mais além de sua prática laboral concreta e orienta sua específica cosmovisão como membros de um coletivo determinado (PALENZUELA, 1995, p. 13 apud TIRIBA, 2001, p. 230). 
Nesta perspectiva, mediadas por processos educativos, diferentes culturas do trabalho dão origem a diversos significados do trabalho. Quando se analisa o trabalho em um determinado tempo e espaço histórico, uma determinada cultura do trabalho possibilita o estabelecimento de relações e a compreensão das mediações entre os aspectos objetivos e subjetivos na formação humana (TIRIBA, 2001).

Segundo Tiriba e Fischer (2013), atualmente, três importantes espaços/tempos

do trabalho de produzir a vida associativamente convivem e se entrelaçam: (i) espaços/tempos revolucionários, (ii) espaços/tempos da atual crise do capital e do trabalho assalariado, (iii) espaços/tempos das culturas milenares das comunidades e

povos tradicionais. Ainda que contraditoriamente, nestes espaços/tempos estão presentes elementos da produção associada e da autogestão do trabalho e da vida social. Além disso, são atravessados por mediações de primeira e de segunda ordem 7 .

Importa, para efeito deste estudo, o segundo espaço/tempo do trabalho de produzir a vida associativamente em que se situam as experiências econômicas dos setores populares que se constituem em estratégias associativas de trabalho e de sobrevivência. No atual contexto do capitalismo, essas unidades de produção 8 "[...] podem se plasmar a produção associada, entendida na perspectiva marxiana, como unidade básica da sociedade dos produtores livres associados". (TIRIBA; FISCHER, 2013, p. 533).

Uma cultura do trabalho de novo tipo, do ponto de vista político e ideológico, tem como pressuposto novas relações de produção que tenham como características o valor de uso e não de troca, a propriedade coletiva dos meios de produção e a socialização do saber ao conjunto os trabalhadores. A partir dessas novas relações de produção, o homem seria capaz de recuperar o sentimento de produtor e sujeitocriador de si mesmo e da história. Uma cultura do trabalho de novo tipo, em última instância, exige uma sociedade de novo tipo (TIRIBA, 2001).

Para Tiriba (2001), o fenômeno dos empreendimentos geridos pelos trabalhadores difere das experiências de produção associada e, em especial, dos conselhos operários nas primeiras décadas do século XX. Esse fenômeno é resultado

\footnotetext{
7 Mediação de primeira ordem: o trabalho como atividade produtiva autodeterminada, elemento fundante do ser do humano; Mediação de segunda ordem: o trabalho organizado pela divisão capitalista do trabalho.

${ }^{8}$ Denominadas, atualmente, de cooperativas populares, associações, grupos de produção comunitária, grupos de produção associada, empreendimentos econômicos solidários, organizações econômicas populares, entre outras (TIRIBA; FISCHER, 2013).
} 
da própria excrescência dos processos de exclusão social e não tem por objetivo a sociedade dos produtores livres associados. Por isso, a autora coloca que os pressupostos de uma nova cultura do trabalho, não podem ser pensados como se, na atualidade, se estivesse vivendo um processo revolucionário" 9 .Temos de analisar os elementos embrionários de um novo sentido do trabalho a partir das condições concretas de espaço e tempo atual em que vivemos, buscando aprender suas mediações" (TIRIBA, 2001, p. 345).

A cultura do trabalho é uma realidade dinâmica e representa "[...] a síntese das condições de trabalho e das relações que os trabalhadores associados estabelecem entre si e com a sociedade" (TIRIBA, 2006, p. 120). A cultura do trabalho é um conjunto de conhecimentos e valores que se plasmam nos processos produtivos associativos e implica a intercessão do conceito de trabalho e de cultura. "Ao trabalhar, os trabalhadores associados produzem cultura e, ao mesmo tempo, trabalham de acordo com uma determinada cultura" (TIRIBA, 2006, p. 120).

O desenvolvimento de uma cultura própria do trabalho associado acontece à medida que se reconhece a cultura do trabalho assalariado, suas possibilidades e seus limites históricos sob a perspectiva da classe trabalhadora. Ao se reconhecerem os processos de continuidade e ruptura, constrói-se com e entre os trabalhadores a análise das relações históricas entre o "velho" e o "novo" (de modos de produção da existência), em outras palavras, do "novo" que está nascendo no seio do "velho" ou, ainda, das continuidades e descontinuidades históricas (TIRIBA; FISCHER, 2009, p. 296).

No trabalho associativo e na vida cotidiana da classe trabalhadora existe uma grande quantidade de saberes produzidos, sendo que, "[...] o saber do trabalhador é a síntese dos saberes apreendidos ao longo da vida, no mundo do trabalho assalariado, na produção associada e em todos os espaços [...] compartilhados" (TIRIBA, 2006, p. 6). Por isso, de acordo com a autora, levando-se em conta o momento histórico, é preciso olhar e compreender as bases materiais e imateriais que

\footnotetext{
${ }^{9}$ Difere, por exemplo, do processo que aconteceu na Comuna de Paris. "A Comuna (1871), conhecida como a primeira manifestação verdadeiramente revolucionária da luta de classes na história moderna, representou a emancipação da classe operária caracterizada como uma emancipação coletiva, superando o trabalho alienado pela socialização das atividades e de poderes públicos, enfrentando a dominação da classe burguesa e do estado, negando a propriedade privada e do capital. A classe operária teve o papel primordial de governar o país; o proletário teve o poder nas mãos. Porém, tal experiência não logrou êxito por muito tempo: o governo francês fez a contrarrevolução tomando o poder novamente" (LUIZ, 2013, p. 45).
} 
propiciam a construção desses saberes produzidos pelo povo, na prática de trabalho e nas demais instâncias das relações sociais (TIRIBA, 2006).

Assim como na fábrica capitalista, à medida que os trabalhadores associados "[...] aprendem os conhecimentos técnicos para produção, apreendem também os valores e comportamentos que são necessários para o estabelecimento de determinadas relações sociais de produção" (TIRIBA, 2006, p. 121).

Uma nova cultura do trabalho necessita de aprendizado e não basta apenas idealizar o trabalho associativo e solidário, é preciso materializá-lo no cotidiano da produção. Na dinâmica do processo produtivo se adquirem e se produzem saberes, afinal, o processo pedagógico é elemento da cultura do trabalho que media as condições objetivas e subjetivas da produção (TIRIBA, 2007).

A expressão saber(es) do trabalho associado é utilizada para designar $\mathrm{o}(\mathrm{s})$ saber(es) produzido(s) pelos trabalhadores e trabalhadoras nos processos de trabalho que se caracterizam, entre outros, pela apropriação coletiva dos meios de produção, pela distribuição igualitária dos frutos do trabalho e pela gestão democrática das decisões quanto à utilização dos excedentes (sobras) e aos rumos da produção (TIRIBA; FISCHER, 2009, p. 293).

Para Tiriba e Fischer (2009), estes saberes, frutos da própria atividade do trabalho, são concebidos e acumulados ao longo da experiência histórica dos trabalhadores que, contrapondo-se à lógica do sistema capital, se associam de forma coletiva, autogestionária.

\begin{abstract}
A palavra saber é utilizada como sinônimo de conhecimento, envolvendo os aspectos materiais, intelectuais e subjetivos presentes na atividade do trabalho e sendo entendido como resultante dos processos prático-teóricos de transformação e compreensão da realidade humano-social. O conceito relaciona-se às ideias de práxis, saber popular, saberes da experiência, conhecimento tácito, trabalho como princípio educativo, produção de saberes em situação de trabalho, produção e legitimação de saberes do/no trabalho. (TIRIBA; FISCHER, 2009, p. 293).
\end{abstract}

Aos sujeitos que estão envolvidos em iniciativas de trabalho associado é necessário o desenvolvimento da práxis crítica, ou seja, identificar, reconhecer, analisar, criticar e legitimar os saberes e experiências. Para Tiriba e Fischer (2009, p. 296) tratam-se "[...] de saberes e experiências produzidos em atividades pregressas de trabalho assalariado (emprego ou subemprego), na relação de continuidade e de 
ruptura com a experiência e os saberes produzidos no ambiente de trabalho associado".

No entanto, esta tarefa consiste em um grande desafio para aqueles que interromperam o processo de escolarização devido à necessidade de buscar condições para sobreviver. Afinal, é necessária a "[...] apropriação dos instrumentos teórico-metodológicos que lhes permitam compreender os sentidos do trabalho e prosseguir na construção de uma nova cultura do trabalho e de uma sociedade de novo tipo" (TIRIBA; FISCHER, 2009, p. 294). Ainda, segundo as autoras, pesquisas indicam que nas organizações econômicas associativas o conhecimento constitui-se como um calcanhar-de-aquiles.

Enquanto Tiriba (2001) se debruça sobre o processo educativo e a cultura do trabalho na produção associada, Faria $(2011,2017 \mathrm{a}, 2017 \mathrm{~b})$ se preocupa com a questão do poder, controle e gestão dessas organizações.

Neste sentido, entende-se que ambas as abordagens desses autores podem se complementar, contribuindo uma para com a outra. Por isso, serão apresentadas as unidades produtivas que poderão vir a ser células para uma autogestão social e quais as condições necessárias para que se efetive uma gestão democrática do processo de trabalho, característica essencial da autogestão.

\section{As Organizações Coletivistas de Produção Associada - OCPA e as condições para uma gestão democrática do processo de trabalho}

Em seu artigo Autogestão, economia solidária e organização coletivista de produção associada: em direção ao rigor conceitual, Faria (2017b), procura delimitar conceitualmente e, assim, distinguir as experiências autogestionárias enquanto fenômenos que apesar de parecerem similares são diferentes. Nesta perspectiva, discute os conceitos de autogestão, economia solidária ${ }^{10} \mathrm{e}$ organização coletivista de produção associada - OCPA.

\footnotetext{
10 "As discussões sobre economia solidária, enquanto projeto dos trabalhadores em direção a outro modo de produção, estão carregadas de equívocos, ao mesmo tempo histórico e de ordem teóricoconceitual. O que se pode observar é que a leitura da história da luta dos trabalhadores é enviesada por uma concepção teórica confusa e pouco rigorosa, ao mesmo tempo que a questão teóricoconceitual é fragilizada por uma análise histórica fragmentada e superficial. Trata-se de uma desarmonia entre teoria e realidade histórica" (FARIA, 2017b, p. 635).
} 
O uso impreciso ou genérico de conceitos não apenas cria dificuldades de análise da realidade, mas é um obstáculo à sua transformação. Ainda que a realidade não seja transformada pela via da ideia ou do conceito, mas da prática que constitui suas relações sociais, a precisão conceitual é fundamental para que se estabeleça uma análise crítica da realidade e das necessárias intervenções que nela os movimentos sociais coletivos necessitam fazer. Não se pode atribuir a um processo, cujos desdobramentos históricos sequer se desenvolveram, a condição de ser ele mesmo já seu fim último (FARIA, 2017b, p. 647).

O autor defende o argumento de que "[...] a autogestão plena somente pode ser concebida no plano social, como um modo de produção, entendido este como a forma dominante de organização da sociedade na produção de suas condições materiais de existência" (FARIA, 2017b, p. 631). A partir da dimensão social da autogestão, o autor afirma que, somente quando o sistema social for autogestionário, poderá existir uma autogestão nas unidades produtivas e, por isso, distingue ${ }^{11} \mathrm{o}$ conceito já estabelecido de autogestão social das experiências que contém características autogestionárias.

Com isso, evita-se de atribuir uma falsa condição de universalização às experiências singulares. "Embora fundamentos importantes do capitalismo já estivessem presentes no modo de produção feudal, foi histórica, social e economicamente necessário que o sistema de capital superasse o sistema feudal para se tornar um modo dominante de produção" (FARIA, 2017b, p. 647).

Por seu turno, para as experiências com características predominantemente autogestionárias - que se constituem em unidades no sistema de capital na medida estão inseridas em sua lógica -, o autor designa o conceito de organizações coletivistas de produção associada - OCPA. Segundo Faria (2017b, p. 629) "[...] os empreendimentos chamados de autogestionários não constituem uma autogestão, mas OCPA, as quais têm características autogestionárias e apresentam-se enquanto formas de resistência ou modelos alternativos aos do sistema de capital".

\footnotetext{
11 "A distinção entre autogestão e empreendimentos com características autogestionárias não é um preciosismo acadêmico, mas uma necessidade crítica que permite avaliar com rigor a potência desses empreendimentos. A sobreposição conceitual exprime uma falsa análise da realidade, criando um obstáculo à reflexão crítica sobre ela. Nesse sentido, é preciso indicar, de saída, que nem a economia solidária é uma autogestão social e nem as OCPA são uma nova economia ou um novo modo de produção" (FARIA, 2017b, p. 631).
} 
A transformação radical da sociedade e a subversão do capitalismo exigem um novo modo material de produção e, segundo Faria (2009), a autogestão social corresponde a um novo modo de produção a ser construído pelo movimento autogestionário coletivista. Modo este que, primeiramente, precisa se realizar nas unidades produtivas através das organizações coletivistas de produção associada OCPA $^{12}$. As OCPA serão células de autogestão em um modo de produção autogestionário.

Enquanto processo de construção histórica e sob certos limites, dada sua inserção no modo de produção capitalista, as OCPA são formas inacabadas de transição para uma autogestão social e, que, em pequena escala, são elementos de contradição do sistema de capital estruturados na direção contrária a heterogestão (FARIA, 2017b).

As OCPA, no sistema de capital, "[...] têm características autogestionárias (autogestão restrita), mas ainda não se consolidaram como empreendimentos autogestionários plenos, pois, para tanto, demandam inserção em um modo de produção autogestionário ou em uma autogestão social" (FARIA, 2017b, p. 642). No entendimento do autor, as OCPA ainda não se consolidaram nem como uma alternativa de superação e nem como negação do sistema capitalista no qual se encontram paradoxalmente inseridas. Afinal, constituem estruturas simples organizadas sobre as bases capitalistas primárias ou mesmo pré-capitalistas e em posição de recusa à lógica da organização capitalista de trabalho.

A autogestão plena, social, é contemplada e ao mesmo tempo contempla a gestão coletivista de trabalho associado, a qual se concretiza em OCPA. No entanto, a OCPA, ela mesma, não constitui a autogestão e nem se constitui em uma autogestão, pois esta não está dada de antemão em experiências singulares. Suas précondições são aquelas de superação do sistema de capital e de todas as suas contradições, mas sua forma e seu conteúdo real somente podem ter materialidade na prática política dos que forem sujeitos de sua construção (FARIA, 2017b, p. 634).

O conceito de autogestão, como argumenta Faria (2017b), deve ser entendido como negação da heterogestão e não em sua materialidade empírica. Isto porque, tal

${ }^{12}$ Em seu livro "Gestão Participativa: Relações de Poder e de Trabalho nas Organizações", Faria (2009) utiliza o termo Organização Solidárias de Produção-OSP que posteriormente foi substituído por Organização Coletivista de Produção Associada-OCPA. Tal alteração se justifica pelo fato de que os trabalhadores se organizam coletivamente em empreendimentos para produzir suas condições de vida. 
conceito tem sido utilizado para definir processos de gestão que "[...] embora tenham determinadas características autogestionárias, não observam completamente todos os elementos constitutivos essenciais de uma autogestão, ou seja, não se constituem em negação absoluta da heterogestão, em sua oposição" (FARIA, 2017b, p. 630).

Em meio à sociedade capitalista, no entanto, é preciso considerar que desenvolver um processo autogestionário consiste num grande desafio para as organizações que se propõem este objetivo. As ações e relações por elas estabelecidas se dão neste espaço, sendo que, "[...] todo o tempo será necessário estabelecer relações de (inter)dependência - ou mesmo de enfrentamento (autogestão como antítese) - com o mundo capitalista em que se encontra" (FARIA, 2017b, p. 634).

O conceito de OCPA refere-se a uma organização de produção - não a uma economia - que tem a produção das condições materiais de existência de uma comunidade específica e politicamente localizada como finalidade ou característica. Além disso, possui um núcleo em torno do qual se constroem os vínculos sociais comuns e, apresenta uma forma de gestão coletivista de trabalho com característica autogestionárias no nível da unidade de produção. As OCPA apresentam características predominantemente autogestionárias e são regidas "[...] por princípios autogestionários de participação coletiva nas decisões, cooperação isonômica no trabalho, auto sustentação restrita à unidade produtiva, desenvolvimento de certa responsabilidade política" (FARIA, 2017b, p. 644).

As OCPA, adaptando a certo contexto concreta e historicamente determinado, consideram a proposta que está no âmago do conceito de autogestão social. Porém, ainda não se constituem como síntese ou superação do modo capitalista (FARIA, 2017b).

Segundo o autor, tanto na esfera decisória quanto na da propriedade dos meios de produção, essas organizações supõem uma gestão democrática. Autogestão, democracia, participação, igualitarismo, cooperação no trabalho, auto sustentação, desenvolvimento humano e responsabilidade social são os princípios que regem esses empreendimentos cooperativos coletivistas de trabalho (FARIA, 2009).

A OCPA corresponde a uma autogestão parcial. Mesmo se tratando de uma unidade de produção ou de trabalho que possui características autogestionárias ela é parcial, "[...] porque não se realiza plenamente e não se realiza porque se encontra 
inserida no sistema de capital e não em um modo de Autogestão Social" (FARIA, 2009, p. 324).

\begin{abstract}
A autogestão coletivista de trabalho no nível da unidade produtiva (restrita) pode ser definida como um modo de gestão que tem por pressuposto básico as relações de igualdade e a valorização do trabalhador, na medida em que rompe o processo de alienação direta do trabalho ao capitalista particular, expande e estimula a difusão do conhecimento sobre o processo de trabalho, além de destruir a estrutura hierarquizada verticalmente, de modo que todos se tornem conscientes de sua responsabilidade para com o sucesso ou insucesso do empreendimento (FARIA, 2017b, p. 645).
\end{abstract}

Nas organizações autogestionárias, o elemento principal é a participação e, por isso, a democracia é fundamental. A valorização da participação dos membros em todas as esferas da empresa é condição no processo de implantação da autogestão, seja nas questões afetas ao cotidiano da produção, quanto nas questões de políticas e estratégias administrativas da organização (FARIA, 2009).

Para Faria (2009; 2011; 2017a; 2017b) é necessário reclamar por uma gestão democrática do processo de trabalho, uma gestão que seja realizada pelos próprios trabalhadores e que se efetive como projeto coletivo de produção das condições materiais de existência humana.

Em seu livro Poder, Controle \& Gestão, Faria (2017a), além de discutir as formas de controle e de poder presentes nas organizações produtivas, analisa as condições necessárias para que uma gestão do processo de trabalho se efetive como democrática. "Não se trata, assim, da apresentação de um 'modelo não capitalista de gestão', mas da discussão das condições que devem ser observadas para a transformação radical e a superação da gestão capitalista" (FARIA, 2017a, p. 421).

Diante do sistema de capital, negar a alienação significa, segundo Faria (2017a, p. 424), "[...] construir, por meio da prática cotidiana, relações de trabalho que busquem resgatar os princípios da emancipação e integrar novamente, o sujeito à sua atividade de trabalho enquanto essência de sua existência material/social".

Com esta perspectiva, Faria (2017a) afirma ser necessário avaliar as condições de uma gestão democrática do processo de trabalho e, coloca em discussão a "luta pelo reconhecimento social, pela redistribuição material da riqueza produzida, pela representação política paritária nas esferas de decisão e pela realização emocional" 
(FARIA, 2017a, p. 424). Para o autor a materialização dessa luta se dá pelos grupos sociais organizados enquanto resistência e negação do sistema de capital.

A proposição de Faria (2017a) se apoia em Nancy Fraser (2003), uma cientista política norte-americana que se dedica aos estudos dos movimentos sociais e dos conflitos políticos.

Fraser insiste em que os conflitos sociais não podem ser explicados apenas a partir da luta pelo reconhecimento social, mas igualmente através da luta pela redistribuição da riqueza material produzida pela sociedade e pela representação política paritária nas esferas de decisão. Estas três formas, para Fraser, correspondem a três dimensões da justiça: cultural (reconhecimento); econômica (redistribuição); política (representação) (FARIA, 2017a, p. 426).

Reconhecimento social, redistribuição igualitária da riqueza material, representação paritária nas esferas de decisão seriam, então, as três categorias emergentes do ponto de vista analítico. No entanto, para Faria (2017a), a dimensão constitutiva do sujeito coletivo concreto em sua prática racional e emocional não está contemplada por estas categorias e, por isso, sugere a categoria analítica da realização emocional. Para o autor, a categoria analítica da realização emocional resolve este problema "[...] na medida em que esta represente a materialização do sujeito coletivo como componente da prática da luta pelo reconhecimento, pela redistribuição e pela representação" (FARIA, 2017a, p. 427).

Na perspectiva de Faria (2017a, p. 428), "[...] ao materializar (i) o sujeito coletivo no plano do grupo social (reconhecimento e realização) bem como (ii) as formas de organização e de gestão do processo de trabalho e da prática política (redistribuição e representação)", estas categorias delimitam o campo empírico e, por seu turno, também o fazem com o plano epistemológico, metodológico e teórico. 
Quadro 01: Aspirações do Sujeito Coletivo do Trabalho na Vida em Sociedade

\begin{tabular}{|c|c|c|}
\hline $\begin{array}{c}\text { O que o Sujeito } \\
\text { Coletivo do Trabalho } \\
\text { Aspira ser }\end{array}$ & $\begin{array}{l}\text { Categorias de } \\
\text { Análise } \\
\text { Correspondentes }\end{array}$ & $\begin{array}{c}\text { Elementos Constitutivos das Categorias de } \\
\text { Análise }\end{array}$ \\
\hline $\begin{array}{l}\text { Socialmente } \\
\text { reconhecido }\end{array}$ & $\begin{array}{l}\text { Reconhecimento } \\
\text { Social }\end{array}$ & $\begin{array}{ll}\checkmark & \text { Objetivação Normativa; } \\
\checkmark & \text { Inserção nos Espaços Coletivos de Poder } \\
& \text { (relação de pertença); } \\
\checkmark & \text { Definição de um Projeto Social Comum }\end{array}$ \\
\hline $\begin{array}{l}\text { Economicamente } \\
\text { recompensado }\end{array}$ & $\begin{array}{l}\text { Redistribuição da } \\
\text { Riqueza Material }\end{array}$ & $\begin{array}{ll}\checkmark & \text { Distribuição Igualitária da Riqueza } \\
\checkmark & \text { Acesso aos Bens Públicos e à Infraestrutura } \\
& \text { urbana e social } \\
\checkmark & \text { Retribuição Justa pelo Trabalho Realizado } \\
\checkmark & \text { Acesso aos Resultados da Produção Social }\end{array}$ \\
\hline $\begin{array}{l}\text { Politicamente } \\
\text { representado }\end{array}$ & $\begin{array}{l}\text { Representação } \\
\text { Política Paritária }\end{array}$ & $\begin{array}{ll}\checkmark & \text { Acesso às Esferas Públicas de Decisão } \\
\checkmark & \text { Práticas Políticas Coletivas } \\
\checkmark & \text { Inserção na Gramática do Conceito de } \\
& \text { Justiça }\end{array}$ \\
\hline $\begin{array}{l}\text { Emocionalmente } \\
\text { realizado }\end{array}$ & $\begin{array}{l}\text { Realização } \\
\text { Emocional }\end{array}$ & $\begin{array}{ll}\checkmark & \text { Sublimação Coletiva* } \\
\checkmark & \text { Desejo do Reconhecimento do Desejo } \\
\checkmark & \text { Afirmação da Identidade } \\
\checkmark & \text { Satisfação Socialmente Avaliada }\end{array}$ \\
\hline
\end{tabular}

$\left(^{\star}\right)$ No sentido da modificação de um impulso ou energia coletiva original (já instituído), de forma a manifestar outra ação ou atitude que venha a ser aceita e valorizada (legitimada) pela sociedade em razão de que sua finalidade considerada superior do ponto de vista valorativo.

Fonte: Faria (2017a, p. 449)

De acordo com o quadro, a redistribuição igualitária da riqueza material socialmente produzida corresponde à dimensão econômica, o reconhecimento social corresponde à dimensão sociocultural, a representação paritária nas esferas de decisão corresponde à dimensão jurídica-política e a realização emocional corresponde à dimensão psicossocial.

Por sua vez, as respostas quanto às potencialidades e quanto às probabilidades de consolidação de uma gestão democrática ou social residem na compreensão das "[...] condições objetivas e subjetivas pelas quais os sujeitos coletivos produzem suas condições de vida em sociedade" (FARIA, 2017a, p. 453).

Para Faria (2009) as OCPA, ainda que em pequena escala, são a contradição do sistema de capital e não disputam o mesmo terreno, pois atuam na periferia do mercado capitalista, na franja do sistema. Esse fato, segundo o autor "[...] não significa que este é seu único e viável lugar de existência. Significa que, diante da organização capitalista, este é o lugar em que [...] se viabiliza como forma alternativa de organização e gestão" (FARIA, 2009, p. 330). 
Considerando que o enfrentamento se dá sob o modo dominante de produção, em uma disputa econômica e política com empresas capitalistas tradicionais ou modernas esses empreendimentos autogestionários se encontram em desvantagem. Por isso, a área de atuação "[...] tem sido aquela não explorada pelo grande capital, seja porque exige ainda uma grande proporção de trabalho humano com poucas exigências de qualificação técnica, seja porque se trata de uma área de baixa produtividade e lucratividade" (FARIA, 2009, p. 331).

\section{Considerações finais}

A partir da sistematização traçada nos itens: (1) a produção associada e o princípio educativo do trabalho: caminhos para a autogestão social; (2) pedagogia da produção associada: processo educativo e cultura do trabalho; e, (3) as organizações coletivistas de produção associada - OCPA e as condições para uma gestão democrática do processo de trabalho, as lacunas e equívocos conceituais identificados foram, respectivamente, preenchidas e elucidados.

Além disso, considera-se que o objetivo proposto de discutir o princípio educativo da produção associada, apoiando-se nos conceitos pedagogia da produção associada e cultura do trabalho - elaborados por Tiriba - e, nos estudos sobre as condições para uma gestão democrática do processo de trabalho e o conceito de organização coletivista de produção associada - OCPA - desenvolvidos por Faria, foi alcançado através da pesquisa bibliográfica realizada.

Esta, leva a considerar que, no Brasil, os princípios da autogestão não são, necessariamente, a referência dos empreendimentos sob controle dos trabalhadores. Num contexto de diminuição dos postos de trabalho assalariado e diante do consequente aumento da pobreza, esses empreendimentos aparecem como uma resposta dos setores populares para satisfazer às suas necessidades de subsistência (TIRIBA, 2001).

A produção associada, frente ao contexto do trabalho assalariado, segundo Tiriba (2001, p. 93), "[...] pode configurar-se em uma economia de autoajuda coletiva dos excluídos, como 'alívio para os pobres' e como parte integrante do projeto de ajuste do capital”. Sendo assim, em relação à formação de grupos de trabalhadores associados, não se pode afirmar que "[...] é, em si mesma, indício de um futuro 
processo de contra hegemonia e que seus objetivos são antagônicos aos de uma sociedade estruturada em classes sociais" (TIRIBA, 2001, p. 346).

No entanto, as novas formas de geração de trabalho e renda "[...] permitem ao trabalhador estabelecer o trabalho sobre outros parâmetros, descobrindo existir outra forma de produção mais humanizada, menos hierarquizada, menos violenta..." (TIRIBA, 2001, p. 92-93). Isso acontece mesmo que, como afirma Tiriba (2001, p. 92), essas novas formas sejam vistas como uma "manifestação da excrescência do sistema capitalista".

As discussões traçadas apontam que é preciso entender que o cooperativismo e outros empreendimentos associativos são requeridos pelo atual regime de acumulação e regulação social, o capitalismo. São, assim, partes integrantes da reestruturação produtiva. A propriedade dos meios de produção, por si só, "[...] não necessariamente nos indica a possibilidade de criação de uma nova cultura do trabalho. Não é sinônimo de superação das relações capitalistas de produção e tampouco representa, necessariamente, trabalho emancipado" (TIRIBA, 2006, p. 118).

Mais ainda, entender que o projeto de uma nova economia é muito mais que geração de trabalho e renda nas franjas do capitalismo é essencial para materialização dessa utopia (BARROS, 2010). Além disso, é necessário compreender que, como prática social, qualquer estratégia popular de sobrevivência, segundo Tiriba (2001, p. 31), "[...] está permeada por motivações e expectativas que refletem os valores e as concepções de seus atores quanto à vida em sociedade".

Segundo Tiriba (2001, p. 210-211), na produção associada o mundo do trabalho "[...] é princípio e também fim educativo, é fonte de produção de conhecimentos e de novas práticas sociais, é a fonte de produção de bens materiais e espirituais". O processo de trabalho nas unidades econômicas da produção associada se desenvolve como um ambiente de educação, em que se vive um intenso processo educativo. Isso acontece quando o grupo de trabalhadores reflete, de forma crítica e dialógica, os problemas organizacionais da unidade (TIRIBA, 2001).

Segundo a autora, porém, a produção associada, enquanto espaço educativo, não substitui o espaço escolar. Trata-se de uma "educação socialmente produtiva", que é ao mesmo tempo técnica e política. "À medida que seus integrantes aprendem os conhecimentos específicos para produzir os bens materiais para sua sobrevivência, 
aprendem, também, os valores, os comportamentos necessários para o estabelecimento de determinadas relações de produção" (TIRIBA, 2001, p. 213).

Partindo das abordagens de Tiriba e Faria, defende-se neste artigo o princípio educativo da produção associada, o qual se desenvolve nas organizações coletivistas de produção associada sob uma gestão democrática do processo de trabalho, sendo capaz de forjar, a partir da aprendizagem coletiva na e pela práxis, uma nova cultura do trabalho estabelecendo assim novas concepções de trabalho, de vida e de mundo.

Por se tratar de uma discussão teórica, as considerações finais aqui traçadas vem reforçar o posicionamento dos autores pesquisados em afirmar que, a gestão democrática em organizações coletivistas de produção associada ou autogeridas é:

[...] aquela que se encontra sob o comando dos produtores diretos, os quais têm responsabilidades ou interesses recíprocos no processo de produção e se solidarizam a partir de um vínculo social comum ou recíproco, tendo em vista a obtenção de uma condição de emancipação com base no reconhecimento social de si pelos outros do sistema de vida em comum, pela redistribuição igualitária da riqueza material produzida coletivamente, pela participação paritária nas diversas instâncias de decisão e pela realização dos projetos com os quais se encontram emocionalmente comprometidos (FARIA, 2017a, p. 452)

Importante ressaltar que, para os trabalhadores da produção associada, "[...] tornam-se indispensáveis os espaços educativos que privilegiem a socialização e a produção teórica, tendo o saber prático como ponto de partida e os novos saberes e as novas práticas sociais como ponto de chegada" (TIRIBA, 2001, p. 225).

A produção associada, mais que alternativa ao desemprego, é instância capaz de possibilitar a produção de novas concepções de trabalho, de vida e de mundo. É fato que os trabalhadores associados isoladamente não conseguem mudar o mundo, no entanto, "[...] os processos produtivos cuja lógica é a hegemonia do trabalho sobre o capital podem permitir a mudança de postura de seus integrantes frente ao mundo" (TIRIBA, 2001, p. 375).

[...] a potencialidade da economia popular radica-se no fato de que ela pode constituir-se em um amplo processo práxico-educativo, em uma escola que deve ser vivida, não apenas para atenuar os problemas do desemprego, senão também para que os trabalhadores e a sociedade descubram ser possível uma nova maneira de fazer e conceber as relações econômicas e sociais tanto no âmbito do lugar de trabalho, quanto no âmbito de toda a sociedade (TIRIBA, 2001, p. 373-374). 
Além de narrativas históricas de experiências vividas no passado, os registros das experiências de trabalho associado revelam, também, "[...] a reconstrução de visões de mundo que demonstram a densidade das formas de organização do processo de trabalho e de formação de trabalhadores/as como seres históricos [...]" (TIRIBA; MAGALHÃES, 2016, p. 99-100).

$\mathrm{Na}$ produção associada os trabalhadores tem a possibilidade de vivenciar elementos que diferem da fábrica capitalista. "O que se vivencia deixa marcas éticas, políticas, culturais e existenciais, além de inúmeros saberes. Coletivamente também se vivenciam modos de ser, produzir e de se reproduzir material, social e culturalmente" (TIRIBA; FISCHER, 2009, p. 3). E, a partir da compreensão do que vivenciam - do como e do porquê de determinados modos de fazer, pensar ou sentir -, os trabalhadores podem transformar as vivências em experiências do trabalhado associado.

\section{Referências}

BARROS, Josiane Fonseca de. O Projeto Educativo das ITCPs: encontros e desencontros na incubagem de cooperativas populares. In: TIRIBA, Lia; PICANÇO, Iracy. (orgs.). Trabalho e Educação: arquitetos, abelhas e outros tecelões da economia popular solidária. 2. ed. Aparecida, SP: Idéias \& Letras, 2010. p. 189-214.

BRITO, José Eustáquio de. O caráter educativo da produção associada: o aprendizado da autogestão. In: TIRIBA, Lia; PICANÇO, Iracy. (orgs.). Trabalho e Educação: arquitetos, abelhas e outros tecelões da economia popular solidária. 2. ed. Aparecida, SP: Idéias \& Letras, 2010. p. 103-124.

FARIA, José Henrique de. Gestão participativa: relações de poder e de trabalho nas organizações. São Paulo: Atlas, 2009.

FARIA, José Henrique de. As Condições de uma Gestão Democrática Social do Processo de Trabalho: reconhecimento, redistribuição, representação e realização. Curitiba: EPPEO, 2011. Working Paper.

FARIA, José Henrique de. Poder, Controle \& Gestão. Curitiba: Juruá Editora, 2017a.

FARIA, José Henrique de. Autogestão, economia solidária e organização coletivista de produção associada: em direção ao rigor conceitual Cad. EBAPE.BR, v. 15, n. 3, Rio de Janeiro, jul./set. 2017b. p. 629-650.

FRIGOTTO, Gaudêncio. Educação e crise do capitalismo real. 3. ed. São Paulo: Cortez, 1999. 
FRIGOTTO, Gaudêncio. Prefácio. TIRIBA, Lia; PICANÇO, Iracy. O trabalho como princípio educativo no processo de produção de uma "outra economia". In: TIRIBA, Lia; PICANÇO, Iracy. (orgs.). Trabalho e Educação: arquitetos, abelhas e outros tecelões da economia popular solidária. 2.ed. Aparecida, SP: Idéias \& Letras, 2010. p. 9-18.

KOSIK, Karel. Dialética do concreto. 7. ed. Rio de Janeiro: Paz e Terra, 2002.

KUENZER, Acácia Zenaide. Pedagogia da fábrica. São Paulo: Cortez, 1986.

LUIZ, Danuta E. Cantoia. Emancipação e serviço social: a potencialidade da prática profissional - 2. ed. Ponta Grossa: Editora UEPG, 2013.

PISTRAK, Moisey Mikhaylovich. Fundamentos da Escola do Trabalho. São Paulo: Expressão Popular, 2000.

SEMERARO, Giovanni. Da sociedade de massa à sociedade civil: a concepção da subjetividade em Gramsci. Educ. Soc., v. 20, n. 66, p.65-83, abr. 1999.

SEMERARO, Giovanni. Especializados e políticos: trabalhadores "dirigentes" de uma democracia popular. In: TIRIBA, Lia; PICANÇO, Iracy. (orgs.). Trabalho e Educação: arquitetos, abelhas e outros tecelões da economia popular solidária. 2. ed. Aparecida, SP: Idéias \& Letras, 2010. p. 257-274.

TIRIBA, L. Economia popular: a relação trabalho-educação como mediação entre 'mundo da cultura' e 'mundo da produção'. In: XXIII Encontro Anual da ANPOCS, Caxambu, 1999. p. 1-16.

TIRIBA, Lia. Economia popular e cultura do trabalho: pedagogia(s) da produção associada. ljuí: UNIJUÍ, 2001.

TIRIBA, Lia. Cultura do trabalho, produção associada e produção de saberes.

Educação Unisinos, v. 10, n.2, p.116-122, mai./ago. 2006.

TIRIBA, Lia. Educação popular e pedagogia(s) da produção associada. Cad. CEDES, v. 27, n. 71, p. 85-98, jan./abr. 2007.

TIRIBA, Lia. Ciência econômica e saber popular: reivindicar o "popular" na economia e na educação. In: TIRIBA, Lia; PICANÇO, Iracy. (orgs.). Trabalho e Educação: arquitetos, abelhas e outros tecelões da economia popular solidária. 2. ed. Aparecida, SP: Idéias \& Letras, 2010. p. 75-101.

TIRIBA, Lia; FISCHER, Maria Clara Bueno. Saberes do trabalho associado. In CATTANI, Antonio D., LAVILLE, Jean-Louis; GAIGER, Luis Inácio; HESPANHA, Pedro. Dicionário Internacional da Outra Economia. Coimbra: Editora Almedina, 2009, p. 293-298.

TIRIBA, Lia; FISCHER, Maria Clara Bueno. Produção associada e autogestão. In: CALDART, Roseli Salete et al. (Org.). Dicionário da educação do campo. Rio de Janeiro, São Paulo: Escola Politécnica de Saúde Joaquim Venâncio, Expressão Popular, 2012. p. 614-619. 
TIRIBA, Lia; FISCHER, Maria Clara Bueno. Aprender e ensinar a autogestão: espaços/tempos do trabalho de produzir a vida associativamente. PERSPECTIVA, Florianópolis, v. 32, n. 2, p. 527-551, mai./ago. 2013.

TIRIBA, Lia; MAGALHÃES, Lívia Diana Rocha. Lições do trabalho associado: educação, experiência e memória coletiva. Revista HISTEDBR On-line, Campinas, n. 70, p. 87-102, dez. 2016.

TIRIBA, Lia; PICANÇO, Iracy. O trabalho como princípio educativo no processo de produção de uma "outra economia". In: TIRIBA, Lia; PICANÇO, Iracy. (orgs.). Trabalho e Educação: arquitetos, abelhas e outros tecelões da economia popular solidária. 2. ed. Aparecida, SP: Idéias \& Letras, 2010. p. 19-32.

TITTON, Mauro. O Princípio Educativo do Trabalho e o Trabalho enquanto Princípio Educativo: ampliando o debate com os movimentos de luta social. In: Anais da 31 Reunião Anual da ANPED. Caxambú: ANPED, 2008.

VÁZQUEZ, Adolfo Sánchez. Filosofia da práxis. Trad. Maria Encarnación Moya. 2. ed. São Paulo: Expressão Popular, 2011.

Recebido em: 09 de abril de 2018. Aprovado em: 17 de junho de 2018. Publicado em: 22 de novembro de 2018. 